\title{
Serrated polyposis syndrome: a silent killer when undetected
}

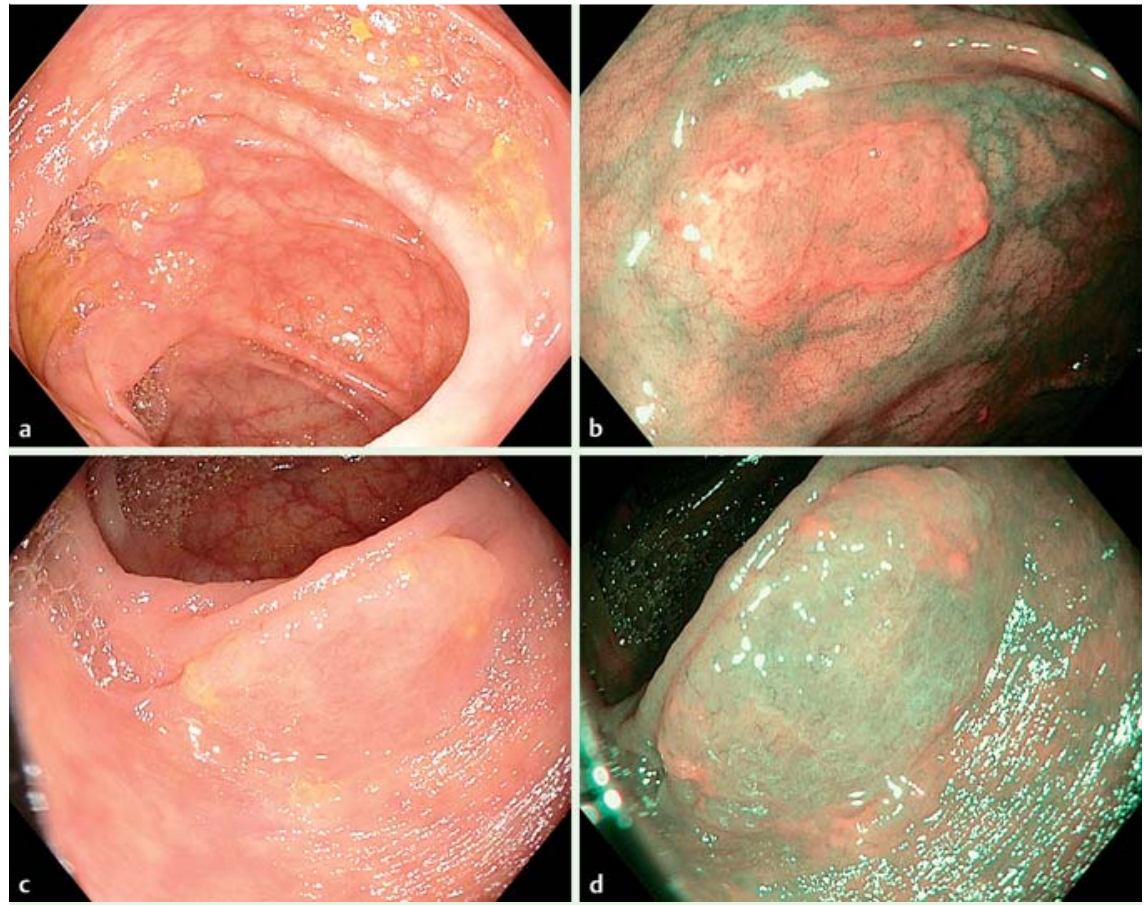

Fig. 1 Representative images of sessile serrated polyps that were missed during the initial colonoscopy. a High resolution white-light endoscopy (HR-WLE) image of the transverse colon showing sessile serrated polyps in the left and right upper quadrants; $\mathbf{b}$ narrow-band imaging (NBI) of the polyp situated in the left upper quadrant showing the characteristic appearance with a covering mucus cap; c HR-WLE image of a large sessile serrated polyp located on a fold (often erroneously described as a thickened fold); $\mathbf{d}$ the corresponding NBI image showing typical features of a sessile serrated polyp including clouded surface, indistinct borders, irregular shape, and dark spots inside the crypts.

This report describes the clinical course of a 59-year-old woman who was diagnosed with metachronous colorectal cancer (CRC). She was diagnosed with a T3 NO MO sigmoid carcinoma in 2002 (at the age of 46) for which she underwent a sigmoid resection and received follow-up at another hospital. Follow-up colonoscopies in 2003 and 2004 did not show any colonic abnormalities, while colonoscopy in 2006 showed a flat polyp in the cecum, which was biopsied. Histopathologic examination revealed a sessile serrated polyp with a focus of dysplasia and surveillance colonoscopy was advised in 3 years. At a subsequent ileocolonoscopy in 2009, no abnormalities were detected in the cecum or elsewhere in the colon and a 5-year surveillance interval was recommended.

During colonoscopy 5 years later (2014), a cecal tumor was detected. Further inspection of the colon did not reveal any other lesions. The patient underwent a right-sided hemicolectomy; histopathologic examination of the resection specimen showed a T2 N0 Mx adenocarcinoma. Furthermore, seven serrated polyps were identified, of which at least five were larger than $10 \mathrm{~mm}$.

The patient was referred to a clinical genetics outpatient clinic elsewhere for analysis of an underlying hereditary cancer syndrome. The clinical geneticist accurately analyzed the family history, which was negative, and requested molecular analysis on the tumor tissue of both CRCs.

The tumor resected in 2002 was microsatellite stable and showed normal expression of the mismatch repair proteins (MLH1, MSH2, MSH6, and PMS2). The tumor resected in 2014 was microsatellite instable and showed loss of function of both MLH1 and PMS2 due to promoter hypermethylation of the MLH1 gene, indicating that this carcinoma had developed via the serrated neoplasia pathway. On the

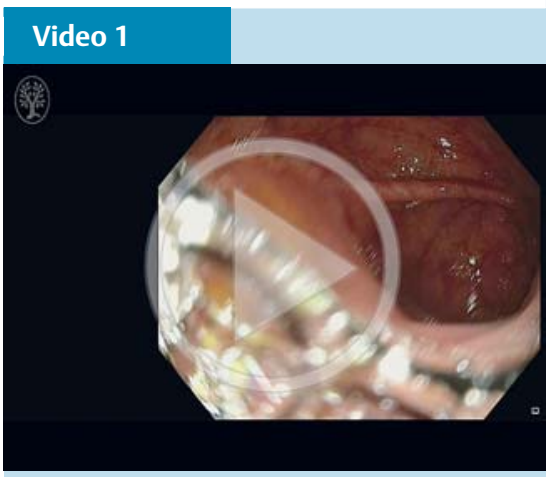

The second-look colonoscopy showing 6 out of the 14 previously missed sessile serrated polyps, using first white-light imaging then narrow-band imaging.

basis of these findings, the patient was diagnosed with serrated polyposis syndrome. Subsequent DNA analysis showed no germline mutation in the MutYH gene [1].

The patient was referred for a second-look colonoscopy, which was performed at our center and demonstrated 14 sessile serrated polyps and 2 hyperplastic polyps up to $15 \mathrm{~mm}$ in size, which were confirmed by histopathology ( $\bullet$ Fig. 1; $\bullet$ Video 1). Surveillance colonoscopy within 1 year was advised.

Serrated polyposis syndrome (SPS), clinically characterized by multiple serrated polyps throughout the colorectum, is accompanied by an increased lifetime risk of CRC [2]. A recent large retrospective study demonstrated that, once cleared from all polyps and under close surveillance, CRC risk in these patients is only moderately increased [3]. However, most cases of SPS remain unrecognized and as a consequence patients do not receive proper surveillance intervals, significantly increasing their risk of developing CRC $[4,5]$. For this reason it is important that endoscopists become acquainted with the diagnosis, risk, and optimal treatment strategies for SPS [6].

Endoscopy_UCTN_Code_CPL_1AJ_2AB

Competing interests: None 


\section{Joep E. G. IJspeert, Barbara \\ A. J. Bastiaansen, Evelien Dekker}

Department of Gastroenterology and

Hepatology, Academic Medical Center, University of Amsterdam, Amsterdam,

The Netherlands

\section{References}

1 Boparai KS, DekkerE, van Eeden Set al. Hyperplastic polyps and sessile serrated adenomas as a phenotypic expression of MYH-associated polyposis. Gastroenterology 2008; 135 : 2014-2018

2 Snover DC, Ahnen DJ, Burt RW et al. Serrated polyps of the colon and rectum and serrated polyposis. In: Bosman T, Carneiro F, Hruban R et al. WHO Classification of Tumours of the
Digestive System. 4th edn. Lyon: World Health Organization; 2010: 160-165

3 Carballal S, Rodríguez-Alcalde D, Moreira L et al. Colorectal cancer risk factors in patients with serrated polyposis syndrome: a large multicentre study. Gut. Epub ahead of print 11 August 2015. DOI: 10.1136/gutjnl-2015309647

4 Boparai KS, Mathus-Vliegen EMH, Koornstra $J J$ et al. Increased colorectal cancer risk during follow-up in patients with hyperplastic polyposis syndrome: a multicentre cohort study. Gut 2010; 59: 1094 - 1100

5 Vemulapalli $K C, \operatorname{Rex} D K$. Failure to recognize serrated polyposis syndrome in a cohort with large sessile colorectal polyps. Gastrointest Endosc 2012; 75: 1206 - 1210

6 La Nauze R, Suzuki N, Saunders B et al. The endoscopist's guide to serrated polyposis. Color Dis 2014; 16: 417-425
Bibliography

Dol http://dx.doi.org/

10.1055/s-0042-101385

Endoscopy 2016; 48: E53-E54

(c) Georg Thieme Verlag KG

Stuttgart · New York

ISSN 0013-726X

\section{Corresponding author}

\section{Evelien Dekker, MD, PhD}

Department of Gastroenterology and Hepatology Academic Medical Centre

Meibergdreef 91105 AZ

Amsterdam

The Netherlands

Fax: +31-20-6917033

e.dekker@amc.uva.nl 